\title{
Geotechnical and Minerology Properties of Marine Clay at the Northeast of Penang Island
}

\author{
Nik Mohd Kamel Nik Hassan ${ }^{1, *}$, Suhaizan Wahid ${ }^{1}$, and Mohd Taha Abd Wahab ${ }^{2}$ \\ ${ }^{1}$ Dr Nik \& Associates Sdn Bhd, Kuala Lumpur, Malaysia \\ ${ }^{2}$ Megaconsult Sdn Bhd, Kuala Lumpur, Malaysia
}

\begin{abstract}
A series of subsurface investigation including in-situ and laboratory tests has been carefully planned and executed for a proposed residential and commercial development over soft marine clay at $\mathrm{Tg}$ Tokong, Penang Island. This paper presents the approach taken in determining and developing fundamental geotechnical engineering design parameters of the soft clay. The subsurface investigation was carried out in two phases to suit the overall development implementation plan namely subsurface investigation done near-shore with about 70 nos of boreholes, 50 nos of cone penetration tests (CPT) and 100 nos of Mackintosh probes and those that were carried out off-shore with 72 Nos of boreholes. The samples extracted from the field work were subjected to grain size analyses, Atterberg limits, oedometer test and consolidated undrained compression. Subsequently, correlations were established between physical soil properties with undrained shear strength from field vane and laboratory tests. The subsurface investigation has suggested that the soft marine clay at the northeast of Penang island comprises of a very soft upper marine clay layer overlying a stiffer lower marine clay. An intermediate stiff clay is sandwiched between these two marine clay layers. The soft clay was also subjected to x-ray diffraction to observe the minerology make up. The primary clay mineral was kaolinite/chlorite followed by smectite. The clay is anticipated to pose minimum effect onto the swelling and compression behaviour.
\end{abstract}

\section{Introduction}

Over the past two decades, land reclamation projects have been undertaken as part of the overall strategy to develop Penang island. The land reclamation projects especially at the northeast of Penang island are underlaid with soft marine clay. The measurement and selection of design soil parameter are essential if wrongly determined such parameters can have significant safety and economical consequence to these projects that are on soft marine clay.

\footnotetext{
* Corresponding author: tahadrnik@gmail.com
} 


\section{Geological Formation and History}

The geological map of Peninsular Malaysia indicates that Penang island is sitting over marine and continental deposits from Quaternary Period. The alluvial deposits generally consist of very soft to firm silty CLAY up to the depth of $20 \mathrm{~m}$ to $30 \mathrm{~m}$ with presence of silty SAND layers. The characteristic of the soft alluvial soils is influenced by the parent material, depositional process, erosion, redeposition, consolidation and fluctuation of tide levels. The formation is covered by old alluvium. The subsurface investigation revealed that the marine clay at the northeast of Penang island consists of upper and lower marine clay layers. The very soft to medium stiff upper clay is due to recent deposits of estuarine origin. The upper and lower clay layers are separated by a layer of medium stiff to stiff clay with thickness in the range of $2 \mathrm{~m}$ to $8 \mathrm{~m}$ and this layer is termed as intermediate desiccated clay resulting from exposure of the seabed to the atmosphere during the fluctuation of sea levels in the geological past.
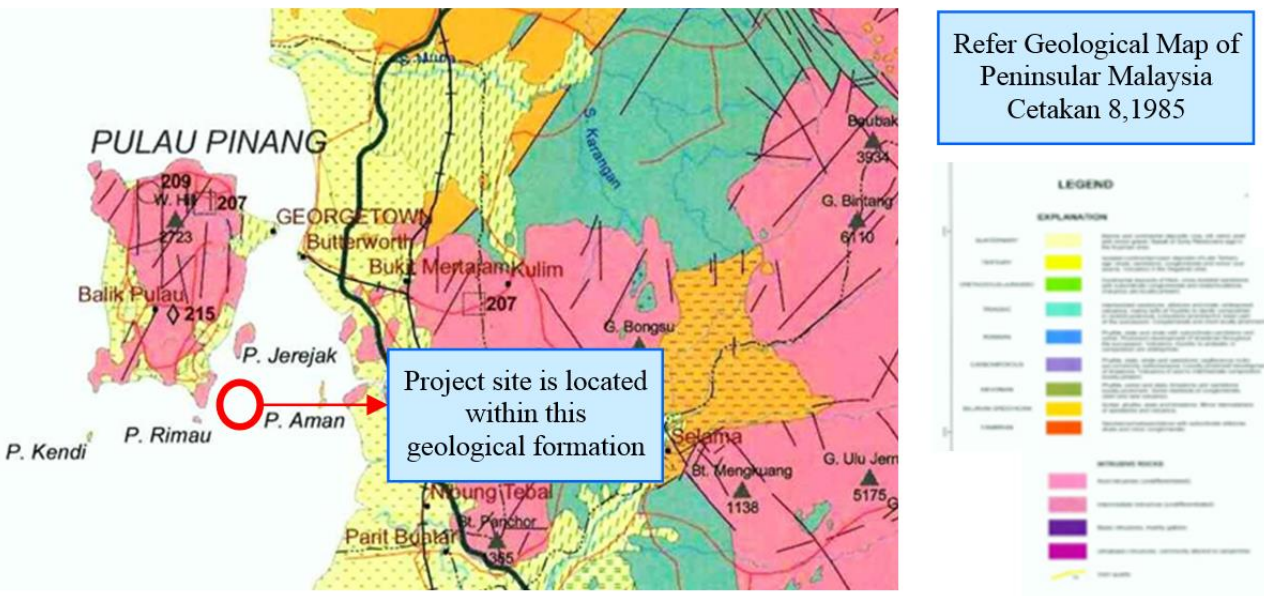

Fig 2.1 Geological Map of Penang Island

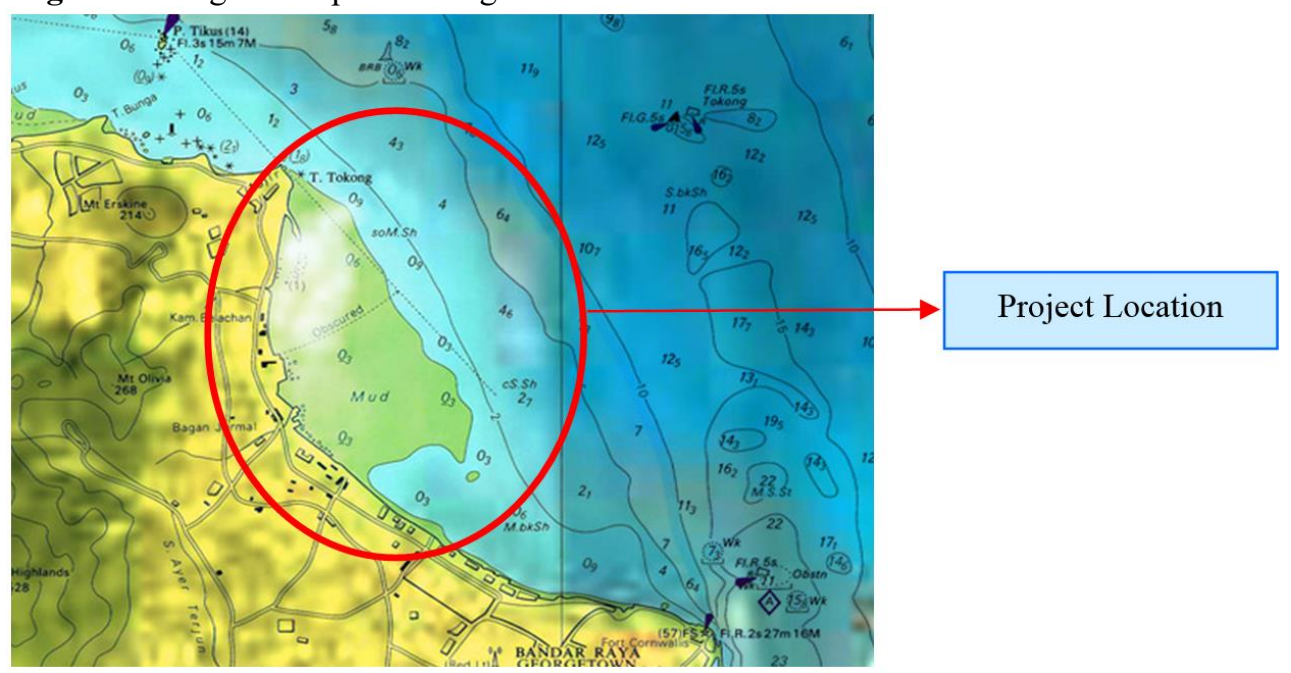

Fig 2.2 Location Map of the Study Area 


\subsection{Subsurface Investigation and Laboratory Testing}

\subsection{Subsurface Investigation}

The subsurface investigation works consist of sinking 142 nos of marine boreholes, conducting 50 nos of field vane shear and plunging 50 nos of cone penetration test. Disturbed and undisturbed samples were collected and tested in the laboratory to study the physical, compression characteristic and mineralogical of the clays. The field vane shear tests were conducted to measure the undrained shear strengths and the sensitivity ratio. Cone penetration test were also conducted as the result give a continuous profile of the soil layers.

\subsection{Laboratory Testing}

Laboratory tests were performed from the samples extracted to determine the geotechnical properties and mineralogy of the clays. Oedometer consolidation test were carried out to establish the compression properties of the clays. The consolidation load was applied in 24hour stages with a load increment ratio of unity according to BS1377 (Part1-9):1990 and Soil Laboratory Testing by K.H Head.

The mineralogy of the clay was determined by extraction of the undisturbed samples for x-ray diffraction. The x-ray diffraction analysis was conducted using diffractometer equipped with cobalt-target tube operated at $45 \mathrm{kV}$ and $40 \mathrm{~mA}$ according to ASTM:STP479.

\subsection{Geotechnical Properties}

\subsection{Test Results}

The borehole logs and results of the laboratory testing were analysed and interpreted values for the following geotechnical parameters were obtained:

- $\quad$ Bulk Density ( $\mathrm{\gamma b})$

- Natural moisture contents (Mc)

- Determinations Liquid Limit (LL) and Plasticity Index (PI)

- Initial void ratio $\left(\mathrm{e}_{0}\right)$

- Pre-consolidation Pressure $(\mathrm{Pc})$

- Compression Index $(\mathrm{Cc})$

- Compression Ratio (CR)

- Over-consolidated ratio (OCR) 

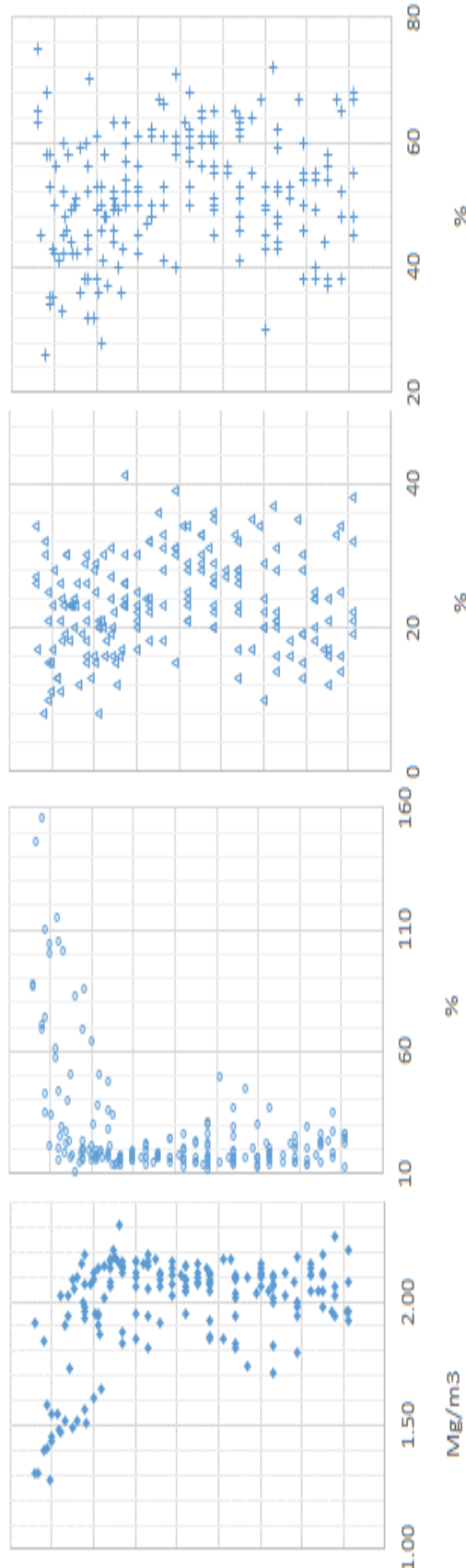

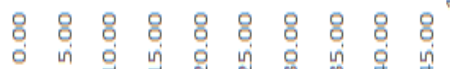

(w) प7da0

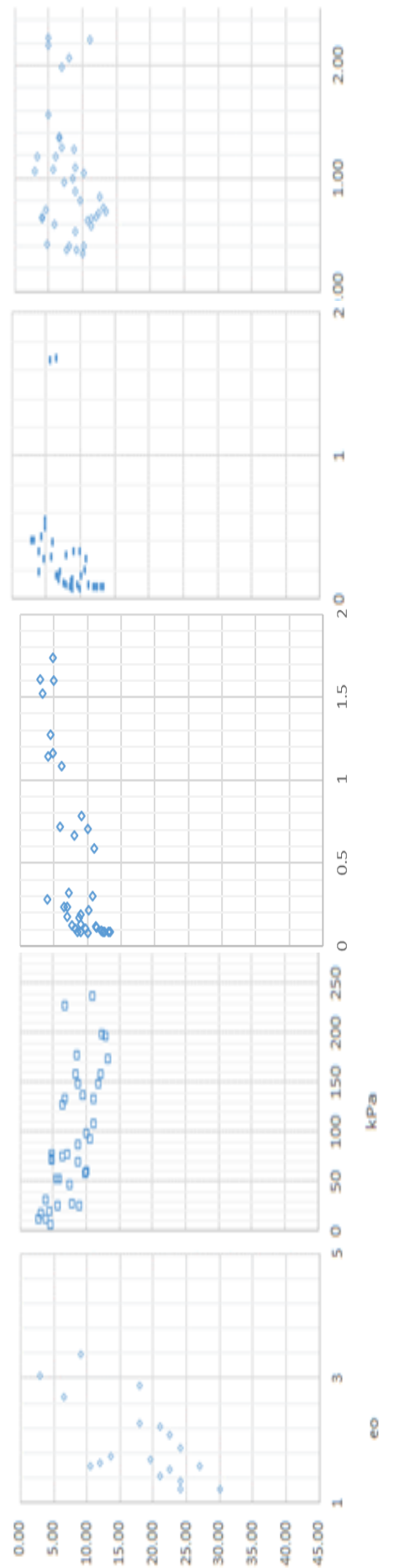

(w) yฉda0 


\subsection{Data Analyses}

\subsubsection{Index Properties}

The position of a soft clay fitted in the plasticity chart well known that the "A" line equation produced a correlation of PI $=0.73 \times($ LL-20), Nagaraj and Jayadeva (1983) for organic clays has obtained a correlation of PI $=0.74 \times$ (LL-8) while Barros and Siveira has produced an equation of PI $=0.74 \times(\mathrm{LL}-17)$ for Brazilian clay. Results from the soil investigation for the clays at the northeast of Penang has suggested a correlation as follows:

$$
\mathrm{PI}=0.897 x(\mathrm{LL}-23.4)
$$

with coefficient of determination $\left(\mathrm{R}^{2}\right)$ of 0.9212

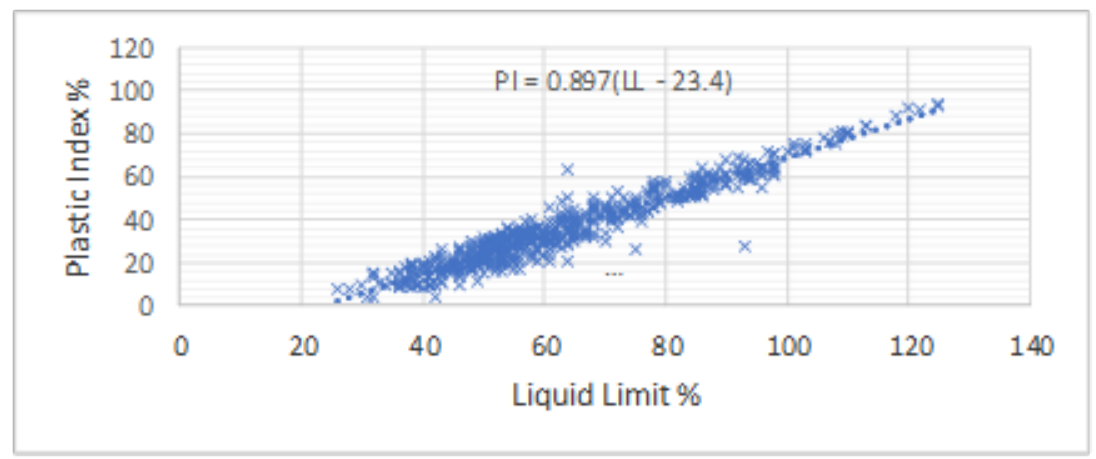

Fig 4.3 Relationship between Plasticity Index (PI) and Liquid Limit (LL)

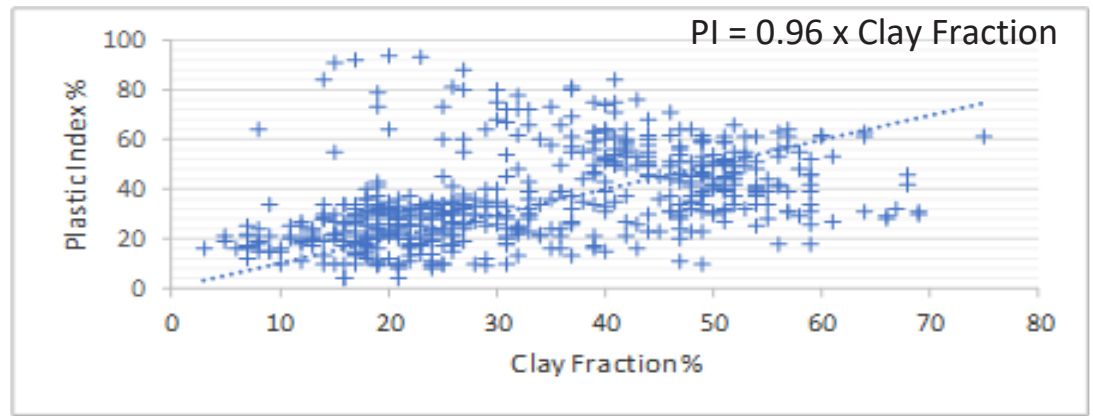

Fig. 4.4 Relationship between Plasticity Index (PI) and Clay Fraction

The activity of the clay can be represented by the slope of the relationship between plasticity index and clay fraction. The clay activity is being controlled by the clay minerology and pore water (Skempton 1953). With regards to the activity index from the soil 
investigation works, the plot of plasticity index versus the clay fraction suggested a relationship as follows:

$$
\mathrm{PI}=0.96 \times \text { Clay Fraction }
$$

demonstrating the soft clay as normal activity in comparison to Singapore clays and Bangkok clays that have activity values of 2.0 and 1.25 respectively (Win Bo 2015). Comparison was made to these two clays because these clays are regarded as Southeast Asian marine clays and are classified as problematic clays.

\subsubsection{Compressibility Properties}

The procedure for evaluating sample disturbance was used to assess each consolidation test as the samples extracted were highly sensitive and being subjected to disturbance due to lack of proper care of samples handling. Correspondingly, the values of $\mathrm{Cc}$ and $\mathrm{Pc}$ were determined based on the corrected field data according to Schmertmann method. The values of pre-consolidation pressure $(\mathrm{Pc})$ and compression index $(\mathrm{Cc})$ are the most commonly used parameter for settlement analysis when oedometer test results are available.

The compressible characteristic of clays, more often than not, is difficult to identify with much confidence because of the high disturbance of the soil samples. Attempts have been made to correlate the values with basic index properties such as natural water content, liquid limit and void ratios. The clays have demonstrated relationships between the compression index and nature water content as follows:

$$
\mathrm{Cc}=0.012(\mathrm{Mc}-5)
$$

with coefficient of determination $\left(\mathrm{R}^{2}\right)$ of 0.6823

The correlation is quite similar with the correlation established by Azzouz (1976) for clays from Greece and United States, with correlation of $\mathrm{Cc}=0.01(\mathrm{Mc}-5)$

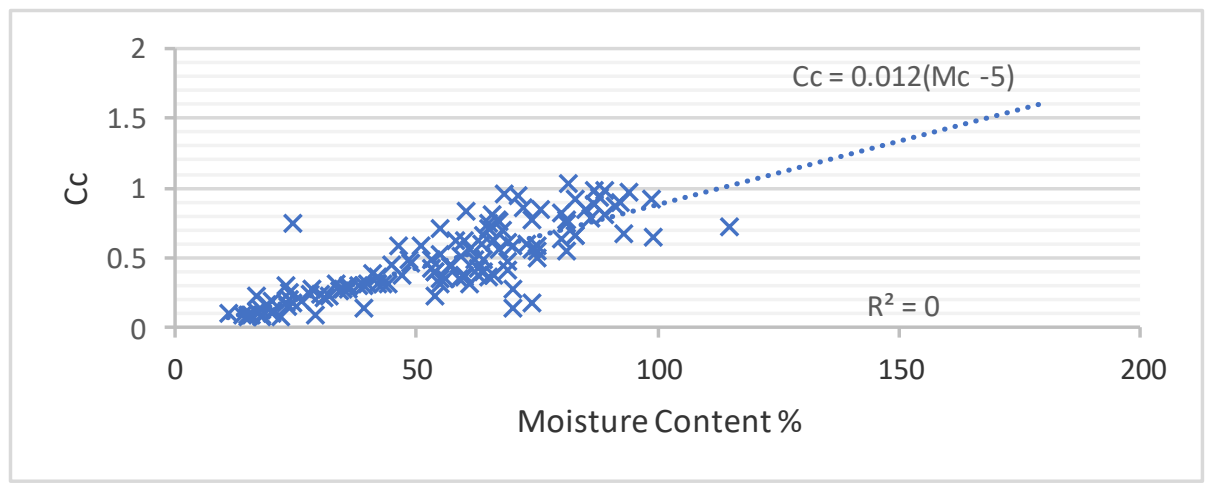

Fig 4.5 Relationship between Compression Index (Cc) and Natural Moisture Content

Many attempts have also be done to correlate the compression index with other basic index property of the clay especially the liquid limit. The fact that the related test for the index is not susceptible to disturbance has made the attempt relatively successful. 


$$
\mathrm{Cc}=0.01(\mathrm{LL}-19.5)
$$

with coefficient of determination $\left(\mathrm{R}^{2}\right)$ of 0.5344

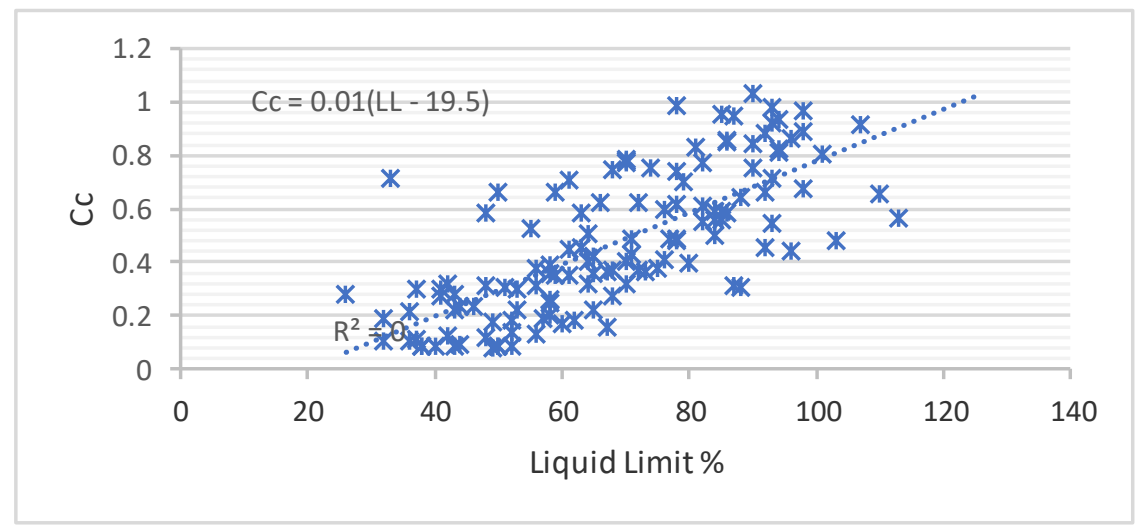

Fig. 4.6 Relationship between Compression Index (Cc) and Liquid Limit (LL)

Many researches have also found that the compression index correlates well with the initial void ratio, which is also influenced by the sensitivity of the clay. From the soil investigation results, two attempts were made to establish a good correlation between the compression index and the initial void ratio by fitting a linear line and a powered line regressions.

For linear regression:

$$
\mathrm{Cc}=0.37722\left(\mathrm{e}_{0}-0.11\right)
$$

with coefficient of determination $\left(\mathrm{R}^{2}\right)$ of 0.7445 , while;

For powered regression:

$$
\mathrm{Cc}=0.3178 \mathrm{e}_{0}^{1.0654}
$$

with coefficient of determination $\left(\mathrm{R}^{2}\right)$ of 0.8193 .

The correlation obtained using linear regression is quite similar with the correlation established by Azzouz (1976) for clays from Greece and United States, by Hough (1972) for inorganic cohesive silt with clay and silty clay and by Rendon-Herrero for American clays The correlations obtained were $\mathrm{Cc}=0.04\left(\mathrm{e}_{0}-0.25\right), \mathrm{Cc}=0.4049\left(\mathrm{e}_{0}-0.3216\right)$ and $\mathrm{Cc}=0.3$ $\left(\mathrm{e}_{0}-0.27\right)$ respectively. However, if compared to the coefficient of determination, the powered regression is a better fit. Therefore, the correlation of the powered regression is more reliable for clays at the Northeast of Penang Island. 


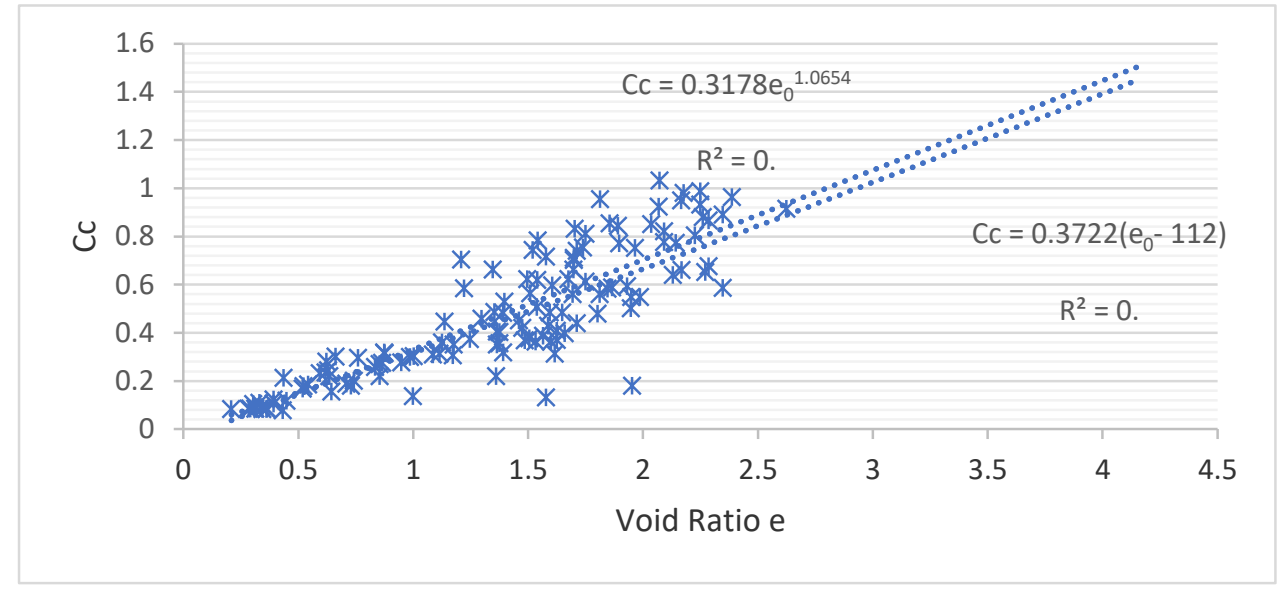

Fig. 4.7 Relationship between Compression Index (Cc) and Initial Void Ratio $\left(\mathrm{e}_{0}\right)$

\subsubsection{Undrained Shear Strength (Field Vane Shear and Cone Penetration Test)}

Undrained shear strength is a soil parameter essential for analysis of embankment stability and bearing capacity of the foundation. Undrained shear strength can be measured directly or indirectly with different equipment, including laboratory and in-situ test. The results of the laboratory test are usually subjected to disturbance of the soft clay, which are commonly analysed and interpreted using established empirical correlations. Undrained shear strength can be measured from in-situ strength tests such as field vane shear and piezocones. The values from these in-situ test were also be subjected to correction according to Bjerrum.

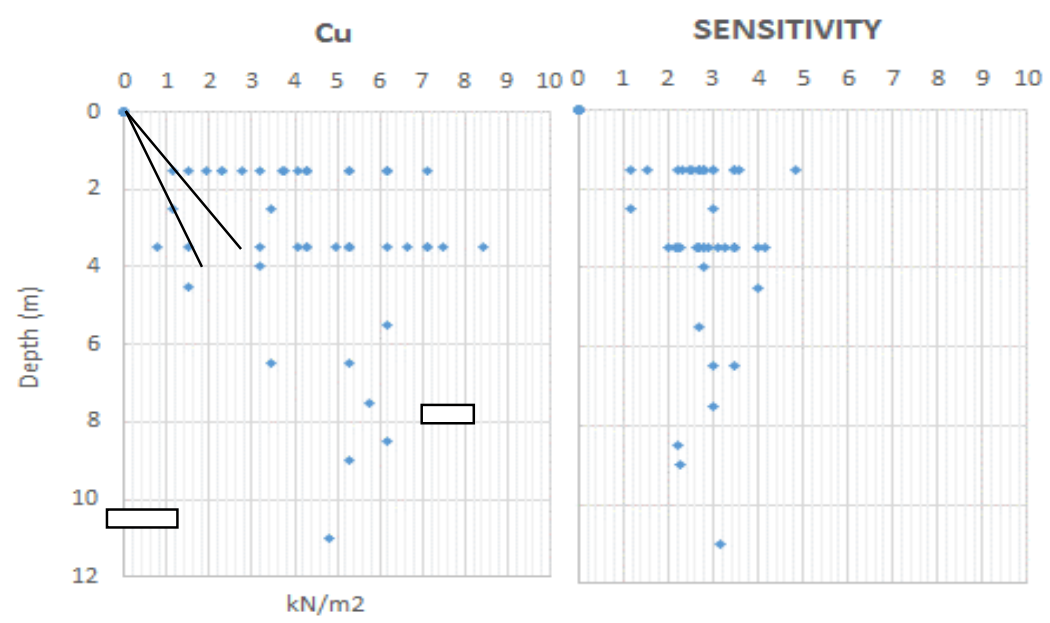

Fig. 4.8 Plot of Depth versus Undrained Shear Strength and Sensitivity Ratio (from field vane shear test) - corrected using Bjerrum method

The values obtained from field vane shear test were also plotted against the established Mesri's plot. Apparently, the values of undrained shear strength obtained from field vane shear fit well between the best fitted line and Mesri's plot. The clays also demonstrated as an average sensitivity values of 3 . Data from cone penetration test were interpreted using 
established correlation as below and being compared to values obtained from in-situ testing (vane shear test).

$$
\mathrm{Cu}=\left(\mathrm{Qt}-\sigma_{\mathrm{vo}}\right) / \mathrm{Nk}
$$

Sensitivity analyses were conducted to derive to the reasonable values of undrained shear strength using Nk of 10, 12 and 15. Results of such analyses are as shown.

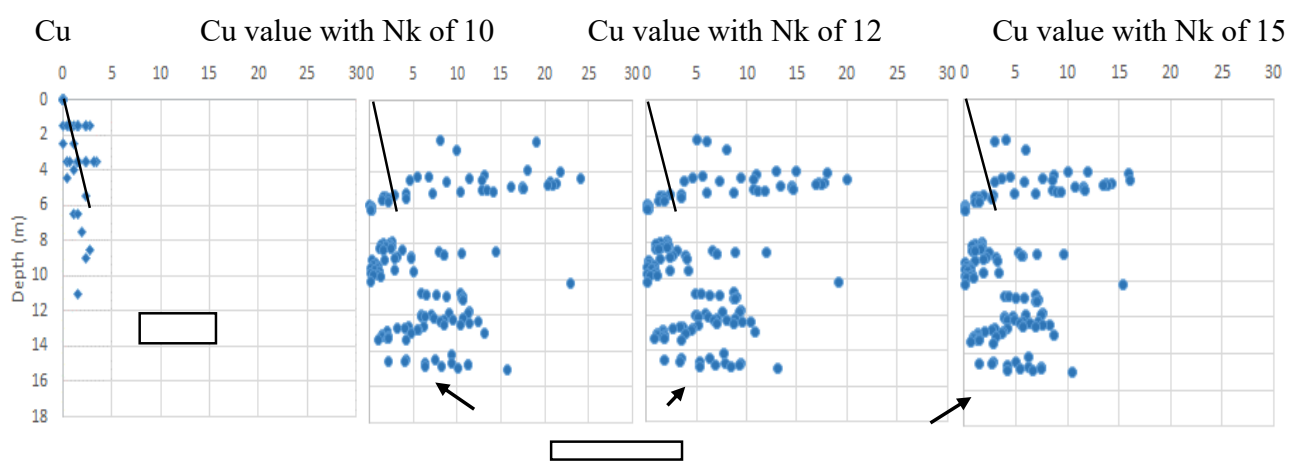

Fig. 4.9 Plot of Corrected Cone Resistance Using Empirical Equation with Correlation Factor (Nk)

For soft clay at the Northeast of Penang Island the Nk values of 12 to 15 seem to correspond well between the best fitted line of the field vane shear and Mesri's plot. To be conservative, for any design work a Nk value of 15 is recommended.

\subsubsection{Mineralogy}

Qualitative analysis of the x-ray diffraction test has concluded that the clay mineral was predominantly Kaolinite/Chlorite. The clay mineral consists of 50\% Kaolinite/Chlorite, $30 \%$ Kaolinite/Illinite and 20\% 20\% Smectite constituents. Due to the bigger proportion of Kaolinite/Chlorite suspension, the clay is anticipated to pose minimum effect onto the swelling and compression behaviour. Thus suggesting that treatment with conventional vertical drain can be successful. Presence of the $20 \%$ Smectite in the clay mineral can be the explanation of the higher liquid limit values compared to natural moisture content obtained in some of the samples. 

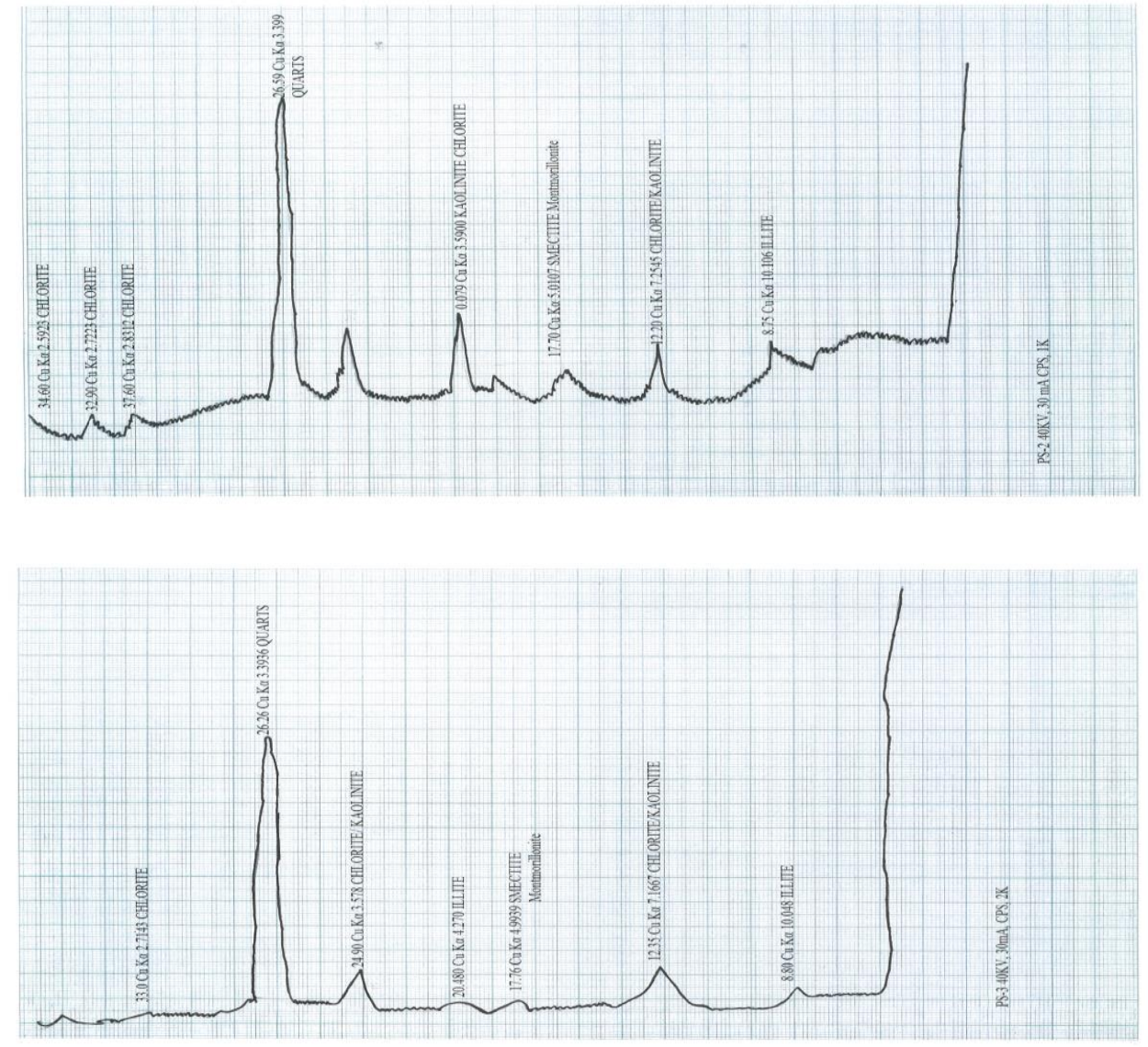

Fig. 4.11 The generalized diffraction diagrams of clay mineral composition

\section{Conclusion}

This paper presented the results of the geotechnical properties and the mineralogy of the soft clay at the northeast of Penang island. The main conclusions are as follows:

- the activity index of the soft clays is about 0.96 which is considered as normal activity.

- the compression ratio is in the range of $0.1-0.4$ while the OCR values are about $50 \%$ under consolidated and $50 \%$ can be considered as over consolidated with OCR exceeding 1.0 .

- the relationships between $\mathrm{Cc}$ and natural moisture content, liquid limit and void ratio were established and are relatively similar to those found in the literature.

- the undrained shear strength increases linearly with depth and showed relatively high value for the upper $2-3 \mathrm{~m}$ due to the clay being desiccated.

- the sensitivity ratio of the clays is between 2 and 4 .

- commonly used empirical correlation has suggested that $\mathrm{Nk}$ values of $12-15$ are appropriate to estimate the reasonable undrained shear strength results from the cone penetration test. 
- the primary constituent of the clay mineralogy was kaolinite/chlorite followed by smectite.

\section{References}

1. A.S. Azzouz, e.a., Regression analysis of soil compressibility, Soil and Foundation, 16, 2 (1976)

2. A.W. Skempton, Activity of clays, The 3rd International Conference on Soil Mechanics Foundation Engineering, 1, 195-200 (1953)

3. B.K. Hough, Basic Soil Engineering (The Ronald Press Company, New York, 1957)

4. J.M.C. Barros, R.M.S. Silveria, C.S. Amaral, Comparison Between Gmáx values obtained from resonant column tests and with bender elements, Proceedings of Brazilian Conf. of Soil Mechanics and Geotechnical Engineering, 14, (2008)

5. M.W. Bo, M.F. Chang, A. Arulrajah, V. Choa, Undrained shear strength of the Singapore marine clay at Changi from in-situ tests. Geotech. Eng. J. Southeast Asian Geotech. Soc. 31, 2 91-107 (2000)

6. O. Rendon Herrero, Journal Geot. Div, Universal compression index equation, 106, GT II, (1980)

7. T.S. Nagaraj, \& M.S. Jayadeva, Journal of Geotechnical Engineering Division, Critical reappraisal of plasticity index of soil, 109, 7 994-1000 (1983) 